\title{
Papaverine-induced QT Interval Prolongation and Ventricular Fibrillation in a Patient with a History of Drug-induced QT Prolongation
}

\author{
Masayuki Goto ${ }^{1}$, Masahito Sato ${ }^{1}$, Hitoshi Kitazawa ${ }^{1}$, Minoru Takahashi ${ }^{1}$, Koichi Fuse ${ }^{1}$, \\ Atsushi Saito ${ }^{1}$, Masaaki Okabe ${ }^{1}$ and Yoshifusa Aizawa ${ }^{2}$
}

\begin{abstract}
A 64-year-old woman underwent a coronary flow reserve evaluation using intracoronary-administered papaverine into the left anterior descending artery. Her baseline electrocardiogram (ECG) was normal, but toward the end of papaverine administration, the QTU intervals were excessively prolonged and torsade de pointes occurred, leading to ventricular fibrillation. Ten months previously, the patient's ECG showed mildly prolonged QTc $\left(480 \mathrm{~ms}^{1 / 2}\right)$, which normalized after the cessation of bepridil. This case report suggests that a history of drug-induced QT prolongation can be a risk factor for papaverine-induced fatal ventricular arrhythmia.
\end{abstract}

Key words: coronary flow reserve, papaverine, QT prolongation, torsade de pointes

(Intern Med 53: 1629-1631, 2014)

(DOI: 10.2169/internalmedicine.53.1828)

\section{Case Report}

We herein describe a case of a 64-year-old woman who had been treated for hypertension and paroxysmal atrial fibrillation. Ten months previously, she had developed chest pain and cold sweats and was transferred to our hospital. Upon admission, her electrocardiogram (ECG) showed mild ST depression in the leads V4-6. Her ECG showed normal sinus rhythm and a normal QT interval of $440 \mathrm{~ms}$, but it showed mildly prolonged QTc $\left(480 \mathrm{~ms}^{1 / 2}\right)$, which normalized after the cessation of bepridil (100 mg/day), which had been administered for atrial fibrillation (Fig. 1A, B). After providing informed consent, the patient underwent coronary angiography, which revealed $90 \%$ stenosis in the right coronary artery, $75 \%$ stenosis in the left anterior descending artery (LAD), and 99\% stenosis in the left circumflex artery. A drug-eluting stent was placed, and the lesion of the left circumflex artery was dilated to $0 \%$ of stenosis. The patient became asymptomatic and was administered antihypertensive drugs (bisoprolol $2.5 \mathrm{mg} / \mathrm{d}$ and imidapril $2.5 \mathrm{mg} / \mathrm{d}$ ) and antiplatelet agents (biaspirin $100 \mathrm{mg} / \mathrm{d}$ and clopidogrel 75 $\mathrm{mg} / \mathrm{d}$ ) and followed in the outpatient clinic. The patient was re-admitted for coronary artery re-evaluation. At the time of catheterization, her blood pressure was $113 / 73 \mathrm{mmHg}$, and her heart rate was 56 beats/min. Her serum potassium was $4.2 \mathrm{meq} / \mathrm{L}$. No re-stenosis was observed at the stenting site. Then, the stenosis of the LAD was evaluated using the coronary fractional flow reserve (FFR) method $(1,2)$. Briefly, a pressure wire (Pressure Wire, Radi Medical Systems, Wilmington, USA) was passed through the stenotic lesion, her blood pressure was recorded during a pull-back, and FFR was calculated as the ratio of the mean coronary pressure distal to the stenosis divided by the mean aortic pressure. FFR $<0.80$ was considered to be an indication for coronary intervention therapy. We administered papaverine hydrochloride to induce the maximal dilatation: $12 \mathrm{mg}$ was administered into LAD in 15 seconds, and FFR was determined at the end of administration $(3,4)$.

The patient's baseline ECG was normal (Fig. 2A), but toward the end of the papaverine administration, the QT and QTU intervals were excessively prolonged, and this was soon followed by torsade de pointes (TdP) and ventricular fibrillation (VF) (Fig. 2B). Her sinus rhythm was resumed

${ }^{1}$ Cardiology, Tachikawa General Hospital, Japan and ${ }^{2}$ Research and Development, Tachikawa Medical Center, Japan Received for publication September 27, 2013; Accepted for publication January 28, 2014 Correspondence to Dr. Yoshifusa Aizawa, aizaways@med.niigata-u.ac.jp 
A

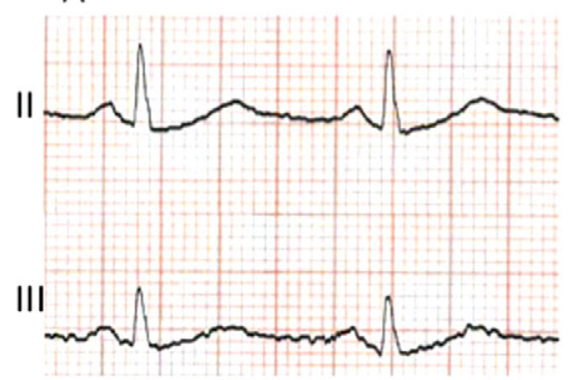

HR $70 \mathrm{bpm}$ QT/QTc $=440 / 480\left(\mathrm{~ms} / \mathrm{ms}^{1 / 2}\right)$
B

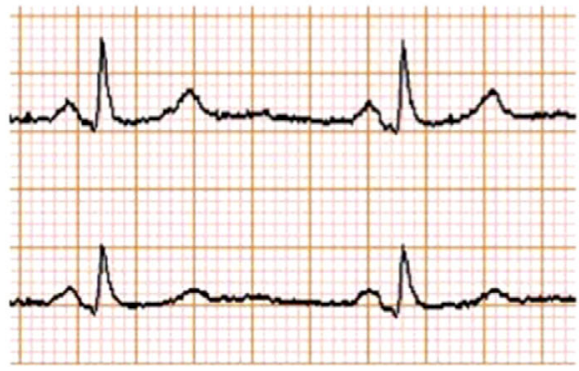

HR $58 \mathrm{bpm}$

QT/QTc $=417 / 419\left(\mathrm{~ms} / \mathrm{ms}^{1 / 2}\right)$

Figure 1. QT prolongation induced by bepridil. A: The patient was administered bepridil for atrial fibrillation. Her heart rate was $70 \mathrm{bpm}$, and QTc was mildly prolonged $\left(480 \mathrm{~ms}^{1 / 2}\right)$. B: After the cessation of bepridil, QTc normalized in a few days $\left(419 \mathrm{~ms}^{1 / 2}\right)$. HR: heart rate, bpm: beats per minute

A
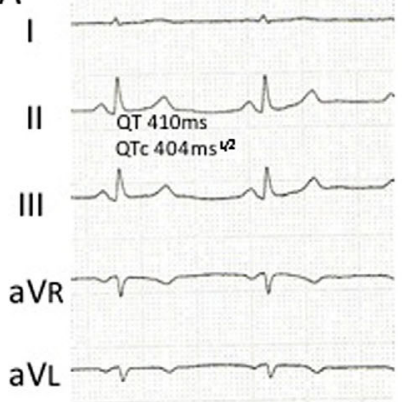

avf r r r r
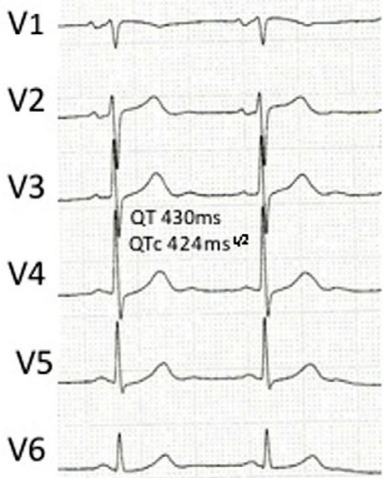

B
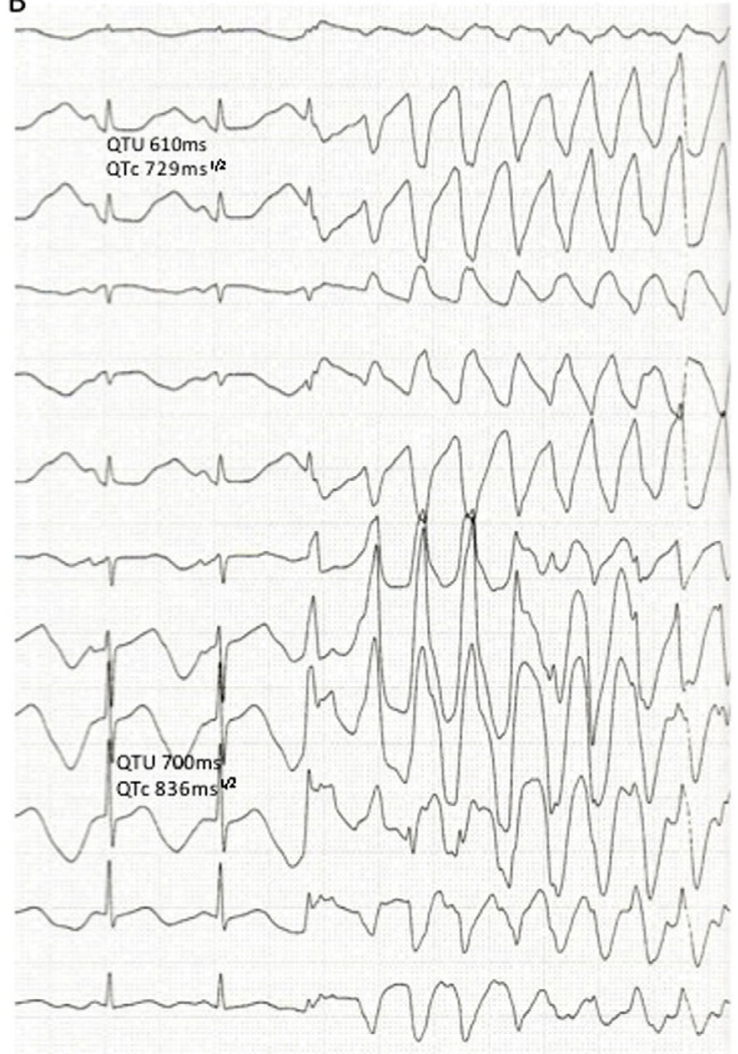

Figure 2. TdP induced by papaverine hydrochloride. A: The patient's ECG was normal before the administration of papaverine: QT and QTc were $410 \mathrm{~ms}$ and $404 \mathrm{~ms}^{1 / 2}$, respectively, in lead II and 430 ms and $424 \mathrm{~ms}^{1 / 2}$, respectively, in lead V4. B: Soon after intracoronary papaverine was administered at a dose of $12 \mathrm{mg}$, the $T$ and $U$ waves were merged, forming a giant T-U wave, and the QTU (QTUc) interval was excessively prolonged to $610 \mathrm{~ms}\left(729 \mathrm{~ms}^{1 / 2}\right)$ in lead II, and $700 \mathrm{~ms}\left(836 \mathrm{~ms}^{1 / 2}\right)$ or longer in V4 with ST-T alteration. Soon after, TdP developed and degenerated to fibrillation.

by a DC shock delivery at $300 \mathrm{~W}$.

Because the FFR value was borderline (0.80), we performed intervention therapy to the LAD lesion, which resulted in $0 \%$ stenosis with stenting. The patient has since been followed uneventfully in the outpatient clinic.

Discussion

The FFR study has been established as a tool to guide coronary intervention therapy with beneficial outcomes $(1,2)$. In the present patient, we employed papaver- 
ine hydrochloride for the FFR study because it can be administered intracoronary and induces a relatively steady-state of maximal hyperemia $(3,4)$.

However, it is known that papaverine may induce fatal ventricular tachyarrhythmia (VTA) (4-7). The mechanism of papaverine-induced VTA is not fully understood (8), but the drug has been shown to inhibit delayed rectifying potassium currents (IKr) and to prolong the action potential duration (9). When the action potential duration is excessively prolonged, early after-depolarization is expected to provoke triggered activity and subsequent VF, as observed in congenital or drug-induced QT prolongation $(10,11)$.

Several risk factors have been suggested for papaverineinduced VTAs, including female gender $(4,6)$, hypokalemia, and alkalosis $(6,7)$. In this report, the patient was female, but she had a normal serum potassium level and sinus rate. However, her history was remarkable for bepridil-induced QT prolongation. Bepridil has been shown to inhibit delayed rectifying potassium currents (IKr and IKs) in animals (12). Bepridil is now used to prevent atrial fibrillation recurrence in Japan, and TdP might rarely develop as an adverse effect (13). Through a common class III action, papaverine and bepridil can cause QT prolongation and TdP, and a history of bepridil-induced QT prolongation can be a risk factor for papaverine-induced VTAs during coronary fractional reserve studies.

A female patient developed TdP and VF following the intracoronary administration of papaverine during a coronary FFR study. A history of drug-induced QT prolongation may be a risk factor for papaverine-induced VTA.

The authors state that they have no Conflict of Interest (COI).

\section{References}

1. Qaseem A, Fihn SD, Dallas P, et al. Management of stable ischemic heart disease: summary of a clinical practice guideline From the American College of Physicians/American College of Cardiology Foundation/American Heart Association/American As- sociation for Thoracic Surgery/Preventive Cardiovascular Nurses Association/Society of Thoracic Surgeons. Ann Intern Med 157: 735-743, 2012.

2. Pijls NH, Fearon WF, Tonino PA, et al; FAME Study Investigators. Fractional flow reserve versus angiography for guiding percutaneous coronary intervention in patients with multivessel coronary artery disease: 2-year follow-up of the FAME (Fractional Flow Reserve Versus Angiography for Multivessel Evaluation) study. J Am Coll Cardiol 56: 177-184, 2010.

3. Tanaka H, Chikamori $\mathrm{T}$, Tanaka $\mathrm{N}$, et al. A flow-limiting stenosis is the major determinant of exercise-induced myocardial stunning in patients with coronary artery disease. J Cardiol 55: 337-344, 2010.

4. Nakayama M, Saito A, Kitazawa H, et al. Papaverine-induced polymorphic ventricular tachycardia in relation to QTU and giant T-U waves in four cases. Intern Med 51: 351-356, 2012.

5. Wilson RF, While CW. Serious ventricular dysrhythmias after intracoronary papaverine. Am J Cardiol 62: 1301-1302, 1988.

6. Talman CL, Winniford MD, Rossen JD, Simonetti I, Kienzle MG, Marcus ML. Polymorphous ventricular tachycardia: a side effect of intracoronary papaverine. J Am Coll Cardiol 15: 275-278, 1990.

7. Zhang X, Shen W, Cai X, Zheng A. Polymorphous ventricular tachycardia after intracoronary papaverine: a report of 3 cases. Chin Med Sci J 8: 248-249, 1993.

8. Kern MJ, Deligonul U, Serota H, Gudipati C, Buckingham T. Ventricular arrhythmia due to intracoronary papaverine: analysis of QT intervals and coronary vasodilatory reserve. Cathet Cardiovasc Diagn 19: 229-236, 1990.

9. Kim YJ, Hong HK, Lee HS, et al. Papaverine, a vasodilator, blocks the pore of the HERG channel at submicromolar concentration. J Cardiovasc Pharmacol 52: 485-493, 2008.

10. Habbab MA, El-Sherif N. Drug-induced torsades de pointes: role of early afterdepolarizations and dispersion of repolarization. Am J Med 89: 241-246, 1990.

11. Kirchhof P, Franz MR, Bardai A, Wilde AM. Giant T-U waves precede torsades de pointes in long QT syndrome: a systematic electrocardiographic analysis in patients with acquired and congenital QT prolongation. J Am Coll Cardiol 54: 143-149, 2009.

12. Wang JC, Kiyosue T, Kiriyama K, Arita M. Bepridil differentially inhibits two delayed rectifier $\mathrm{K}^{+}$currents, $\mathrm{I}_{\mathrm{Kr}}$ and $\mathrm{I}_{\mathrm{Ks}}$, in guinea-pig ventricular myocytes. Br J Pharmacol 128: 1733-1738, 1999.

13. Yasuda M, Nakazato Y, Sasaki A, et al. Clinical evaluation of adverse effects during bepridil administration for atrial fibrillation and flutter. Circ J 70: 662-666, 2006.

(C) 2014 The Japanese Society of Internal Medicine http://www.naika.or.jp/imonline/index.html 